Casas, L., Zock, J.P., Carsin, A.E., Fernandez-Somoane, A., Espluques, A., Santa-Marina, L., Tardón, A., Ballester, F., Basterrechea, M., Sunyer, J. The use of household cleaning products during pregnancy and lower respiratory tract infections and wheezing during early life. International Journal of Public Health: 2013, 58(5), 757-764

\begin{tabular}{|l|l|}
$\begin{array}{l}\text { Postprint } \\
\text { Version }\end{array}$ & 1.0 \\
\hline Journal website & $\underline{\text { http://link.springer.com/article/10.1007/s00038-012-0417-2 }}$ \\
\hline Pubmed link & $\underline{\text { http://www.ncbi.nlm.nih.gov/pubmed/23064260 }}$ \\
\hline DOI & $10.1007 /$ s00038-012-0417-2 \\
\hline
\end{tabular}

This is a NIVEL certified Post Print, more info at http://www.nivel.eu

\title{
The use of household cleaning products during pregnancy and lower respiratory tract infections and wheezing during early life
}

Lidia CASAS ${ }^{1,2,3}$, JAN PAUL ZOCK ${ }^{1,2,3}$, ANNE ELIE CARSIN ${ }^{1,2,3}$, ANA FERNANDEZSOMOANO $^{3,4}$, ANA ESPLUGUES ${ }^{3,5}$, LORETO SANTA-MARINA ${ }^{3,6,7}$, ADONINA TARDÓN ${ }^{3,4}$, FERRAN BALLESTER ${ }^{3,5,8}$, MIKEL BASTERRECHEA ${ }^{3,6,7}$ AND JORDI SUNYER ${ }^{1,2,3,9}$

(1) Centre for Research in Environmental Epidemiology (CREAL), Barcelona, Spain

(2) Hospital del Mar Research Institute (IMIM), Barcelona, Spain

(3) CIBER Epidemiología y Salud Pública (CIBERESP), Barcelona, Spain

(4) University of Oviedo, Oviedo, Spain

(5) Center for Public Health Research-CSISP, Valencia, Spain

(6) Subdirección de Salud Pública de Gipuzkoa, Departamento de Sanidad, Gobierno

Vasco, San Sebastián, Spain

(7) Instituto de Investigación Sanitaria Biodonostia, San Sebastián, Spain

(8) University of Valencia, Valencia, Spain

(9) Pompeu Fabra University, Barcelona, Spain

\begin{abstract}
Objective: To evaluate the effects of household use of cleaning products during pregnancy on infant wheezing and lower respiratory tract infections (LRTI).

Methods: In four prospective Spanish birth cohorts $(n=2,292)$, pregnant women reported the use of household cleaning products. When infants were 12-18 months old, current cleaning product use and infant's wheezing and LRTI were reported. Cohort-specific associations between the use of specific products and respiratory outcomes were evaluated using multivariable regression analyses and estimates were combined using random-effects meta-analyses.

Results: The period prevalence of LRTI was higher when sprays (combined odds ratio $(\mathrm{OR})=1.29$; $95 \%$ confidence interval $(\mathrm{CI})$ 1.04-1.59) or air fresheners ( $\mathrm{OR}=1.29$; CI 1.03-1.63) were used during pregnancy. The odds of wheezing increased with spray $(\mathrm{OR}=1.37$; CI 1.10-1.69) and solvent $(\mathrm{OR}=$ 1.30; CI 1.03-1.62) use. The associations between spray and air freshener use during pregnancy and both outcomes remained apparent when these products were not used after pregnancy. Nevertheless, the estimates were higher when post-natal exposure was included.

Conclusion: The use of cleaning sprays, air fresheners and solvents during pregnancy may increase the risk of wheezing and infections in the offspring.
\end{abstract}


Casas, L., Zock, J.P., Carsin, A.E., Fernandez-Somoane, A., Espluques, A., Santa-Marina, L., Tardón, A., Ballester, F., Basterrechea, M., Sunyer, J. The use of household cleaning products during pregnancy and lower respiratory tract infections and wheezing during early life. International Journal of Public Health: 2013, 58(5), 757-764

\section{INTRODUCTION}

Household cleaning products are used worldwide to maintain the functionality, appearance and appropriate hygienic conditions of our homes. Cleaning products containing disinfectants can be applied to reduce exposure to indoor microbial agents. However, cleaning products contribute to the total burden of exposure to chemicals in the general population and this is an emerging public health issue. Studies on the adverse health effects of cleaning products started one decade ago, focusing on respiratory effects associated with occupational exposure to cleaning products (Jaakkola and Jaakkola 2006; Zock et al. 2010). There is a vast body of evidence that professional use of cleaning products is associated with asthma and other respiratory disorders. In addition to the effects of professional cleaning, the European Community Respiratory Health Survey (ECRHS) found that nonoccupational household cleaning is associated with adverse respiratory health effects in adult users. In particular, common use of cleaning sprays was associated with new-onset asthma (Zock et al. 2007) and frequent use of bleach with respiratory symptoms (Zock et al. 2009).

Potential effects of passive exposure to cleaning chemicals on children's respiratory health have not been evaluated in many studies. Nevertheless, two longitudinal analyses of data from the Avon Longitudinal Study of Parents and Children (ALSPAC) in the UK suggested that frequent use of chemical-based products, predominated by cleaning agents, during pregnancy increased the risk of persistent wheezing before 3 years and at 7 years of age (Henderson et al. 2008; Sherriff et al. 2005). However, these studies did not assess the effects of each specific chemical product and could not determine whether the association was pre- or post-natal. To our knowledge, there are no published studies assessing respiratory health effects of prenatal exposure to specific household cleaning products on respiratory health in infants. Therefore, we aimed to evaluate the effects of household use of cleaning products during pregnancy on respiratory symptoms and airway infections during the first year of life in four birth cohorts in the longitudinal INMA project (Ribas-Fitó et al. 2006), focusing on wheezing and lower respiratory tract infections (LRTI).

\section{METHODS}

\section{Study design and study population}

Population-based birth cohorts were established as part of the INMA [INfancia y Medio Ambiente (Environment and Childhood)] project in several regions of Spain, following a common protocol (Ribas-Fitó et al. 2006). The presented analyses include data from the INMA cohorts of Asturias, Gipuzkoa, Sabadell and Valencia regions, established between 2003 and 2008. Women were enroled during the first trimester of their pregnancy at public primary health care centres or public hospitals, depending on the region. The inclusion criteria were age $\geq 16$ years, intention to deliver at the reference hospital, and singleton pregnancy. Women were excluded if they were unable to communicate in Spanish, Basque or Catalan or had assistance with conception. Women were followed throughout pregnancy; their children were followed from birth to the age of 12-18 months. Written informed consent was 
Casas, L., Zock, J.P., Carsin, A.E., Fernandez-Somoane, A., Espluques, A., Santa-Marina, L., Tardón, A., Ballester, F., Basterrechea, M., Sunyer, J. The use of household cleaning products during pregnancy and lower respiratory tract infections and wheezing during early life. International Journal of Public Health: 2013, 58(5), 757-764

obtained from all participants and the study was approved by the Hospital Ethics Committees in each region.

Trained research personnel administered questionnaires on socio-economic status, health, and environmental exposures, including the use of household cleaning products, at the first and third trimesters of pregnancy and at the age of 12-18 months. Anthropometric measurements were performed by trained midwifes at delivery.

A total of 2,292 (87 \% of the recruited participants) children were followed until 12 18 months of age. In the third trimester of pregnancy, their mothers provided information on the use of cleaning products during the entire gestational period. Information on LRTI and wheezing was available for 2,162 and 2,147 children, respectively. Children included in the study were not different from those not included with regard to most characteristics, although participants had a higher maternal education in Sabadell and Valencia ( $p$ value $<0.05$ ).

\section{Respiratory symptoms and infections during the first year of life}

The respiratory outcomes of LRTI and wheezing during the first year of life were reported by the mothers at the age of 12-18 months through interviewer-led questionnaires. Women were asked about episodes of bronchiolitis, pneumonia, bronchitis, laryngitis or pneumonitis and episodes of wheezing during the first year of the child's life. An individual was classified as ever had a LRTI when the mother answered yes to any of the above-mentioned infections. An additional question was asked regarding the occurrence of any chest infection during the study period; agreement between this question and the report of specific LRTI was $92 \%$ (Sunyer et al. 2010). We classified the child as ever wheezing when the mother reported any wheezing episode during the first year of life.

\section{The use of household cleaning products}

The questionnaire administered in the third trimester of pregnancy included questions about the use of common domestic cleaning products in Spain, such as bleach, ammonia, solvents, furniture polishes, glass cleaners, air fresheners, multiuse cleaners, ironing sprays, floor cleaning sprays, oven sprays and carpet sprays. Additional information on the household use of degreasing products during pregnancy was obtained in two of the four cohorts (Gipuzkoa and Sabadell). In the main analyses, we used a combined spray variable comprising ironing, floor, oven and carpet sprays due to the low frequency of use of the individual specific sprays. This approach is further justified by the fact that the application of cleaning products through spraying is likely to facilitate respiratory exposure (Zock et al. 2007). Although the active chemicals may be qualitatively different, the relevant internal exposure is overall higher as compared to the use of liquid cleaning products. Additional information on the post-natal use of cleaning products at the age of 12-18 months was obtained for the Asturias and Valencia cohorts.

\section{Potential confounders}

The general questionnaire administered during pregnancy included sociodemographic data such as occupational history and education (primary school or less, 
Casas, L., Zock, J.P., Carsin, A.E., Fernandez-Somoane, A., Espluques, A., Santa-Marina, L., Tardón, A., Ballester, F., Basterrechea, M., Sunyer, J. The use of household cleaning products during pregnancy and lower respiratory tract infections and wheezing during early life. International Journal of Public Health: 2013, 58(5), 757-764

secondary school, and university degree or more); biometric, host, and lifestyle data of the biological parents; country of origin of the mother (categorized as "European" and "non-European" in our study); medical data of the current pregnancy; maternal active and passive smoking during pregnancy; and housing characteristics such as gas cooking and heating. Birth weight and date of birth were collected at delivery from medical records. From the date of birth, we created a dichotomous variable that grouped children according to their birth during warm or cold months in Spain (May-October and November-April, respectively). Information on maternal active and passive smoking during the first year of the child's life was obtained from questionnaires administered at months $12-18$. A new four-category variable was computed including information on maternal smoking during pregnancy and information on maternal smoking during the first year of life (never smoked, smoked only during pregnancy, smoked only after pregnancy, smoked during both periods). Social class was obtained from the major group classification of the ISCO-88 (International Standard Classification of Occupations) of the longest held job.

\section{Statistical analysis}

Descriptive statistics included arithmetic means and standard deviations for continuous variables and percentages for categorical variables. Crude associations were evaluated using Student's t test and Chi square test.

Multivariable logistic regression models including potential confounders were developed for both outcomes (LRTI and/or wheeze) for each of the four cohorts, resulting in eight specific models. Any potential confounder with a p value $<0.2$ in the likelihood ratio test or associated with the use of cleaning products was included in the models. Each cleaning product was included separately in each of the eight models. Potential confounders were then excluded from the models if their effect did not modify the association estimate of the cleaning products (e.g. gas heating). Since the prevalence of the outcomes and the use of cleaning products were different for each cohort, random and fixed-effects meta-analyses including the estimates for the four cohorts were performed in order to obtain combined odds ratios (OR) and their $95 \%$ confidence interval (CI) for each cleaning product and outcome. Potential heterogeneity between cohorts was examined using Q statistics. Moreover, a factor analysis was performed to describe patterns of use of the products, and the resulting factors were included separately in the eight previously described regressions and meta-analyses.

Finally, to investigate the exposure to each cleaning product separately during pregnancy and during the first year of life, in Asturias and Valencia, we defined exposure using four categories: never exposed, only during pregnancy, only after birth and during both periods. To obtain an adjusted OR, one multivariable logistic regression per outcome was computed following the same procedure explained above. Random-effects meta-analyses and pooled analyses adjusting per cohort were performed. Since both analyses demonstrated very similar results, we are presenting only the pooled OR. Furthermore, we performed factor analyses to describe the pattern of use of cleaning products at the age of 12-18 months and included the factors in the multivariable logistic models. All statistical analyses were conducted with STATA SE 10.0 statistical software (Stata Corporation, College Station, TX, USA). 
Casas, L., Zock, J.P., Carsin, A.E., Fernandez-Somoane, A., Espluques, A., Santa-Marina, L., Tardón, A., Ballester, F., Basterrechea, M., Sunyer, J. The use of household cleaning products during pregnancy and lower respiratory tract infections and wheezing during early life. International Journal of Public Health: 2013, 58(5), 757-764

\section{RESULTS}

The prevalence of LRTI and wheezing in the first year of life were 32 and $35 \%$, respectively (Table 1). The prevalence of LRTI was higher in Sabadell, whilst wheezing was more prevalent in Asturias. The lowest prevalence of both respiratory outcomes was in Valencia. The most commonly used cleaning products were glass cleaners and bleach, both used in approximately three out of four homes. Multiuse cleaners, air fresheners, furniture polishes and sprays were used by approximately half of the mothers. Solvents and ammonia were used in 28 and $35 \%$ of the homes, respectively.

\section{[TABLE 1]}

Prevalence of LRTI and wheezing was generally higher in infants whose mothers used sprays or degreasing products during pregnancy (Table 1, online supplement), and some of the study covariates were associated with child respiratory health at this age (Tables 2 and 3, online supplement). After adjustment, the odds of LRTI and wheezing increased with the use of spray and degreasing products in all cohorts. Additional adjustment by the age of the infant at the moment of the questionnaire administration did not result in any significant change in the associations. When combining the cohort-specific results by meta-analyses (Table 2), the odds of LRTI and wheezing were 29 and $37 \%$ higher, respectively, in infants whose mothers used sprays during pregnancy. In addition, use of air fresheners was associated with LRTI $(\mathrm{OR}=1.29, \mathrm{CI}=1.03-1.63)$, and the use of solvents with wheezing $(\mathrm{OR}=1.30, \mathrm{CI}=$ 1.03-1.62). The forest plots in Fig. 1 show associations with the use of sprays, solvents and air fresheners, per region and combined, for both outcomes. Indications for heterogeneity were only observed for the association between the use of solvents and LRTI ( $p$ value $=0.06$ ).

\section{[TABLE 2]}

The factor analysis identified three patterns of use of cleaning products (Table 4, online supplement). The first factor discriminated between women who reported using furniture polishers, glass cleaners and air fresheners and somewhat more sprays. A second factor discriminated individuals whose mothers tended to use sprays and solvents. Finally, the third factor discriminated those using bleach and ammonia. After adding the factors separately to each of the eight models and performing meta-analyses, factor 2 was associated with both LRTI $(\mathrm{OR}=1.54, \mathrm{CI}=$ 1.11-2.14) and wheezing ( $\mathrm{OR}=1.68, \mathrm{CI}=1.21-2.35)$ (Table 2).

The analyses conducted in the Asturias and Valencia cohorts to determine the association according to the time window of exposure showed increased odds of LRTI and wheezing in children whose mothers used sprays only during pregnancy compared to never users (adjusted $\mathrm{OR}=1.19$, $95 \% \mathrm{CI}=0.82-1.73$ and $\mathrm{OR}=1.62$, $95 \%$ CI $=1.11-2.36$, respectively) (Table 3). These ORs were higher than those observed for users only after pregnancy. Regarding air fresheners, the highest and significant ORs were observed for exposure only after birth, although the odds were 
Casas, L., Zock, J.P., Carsin, A.E., Fernandez-Somoane, A., Espluques, A., Santa-Marina, L., Tardón, A., Ballester, F., Basterrechea, M., Sunyer, J. The use of household cleaning products during pregnancy and lower respiratory tract infections and wheezing during early life. International Journal of Public Health: 2013, 58(5), 757-764

also increased in children with exposure only during pregnancy (adjusted OR for LRTI 1.31 [95 \% CI = 0.77-2.21] and for wheezing 1.39 [95 \% CI = 0.85-2.29]). Regarding solvents, increased odds of LRTI and wheezing were observed only when this exposure was during pregnancy and the first year of life (adjusted OR for LRTI 1.35 [95 \% CI = 0.73-2.50] and for wheezing 1.81 [95 \% CI = 0.98-3.37]). A description of the time window of use of these three products in the Valencia and Asturias cohorts is provided in Table 2 of the online supplement.

\section{[FIGURE 1][TABLE 3]}

Finally, the factor analyses using the cleaning products' variables at the age of 12-18 months identified three patterns. These factors discriminated the same patterns of cleaning product use as the ones identified for the during pregnancy time window. The OR obtained after including the factors in the multivariate models was not different from those obtained for the pregnancy patterns (data not shown).

\section{DISCUSSION}

We observed that domestic use of cleaning sprays, air fresheners and solvents during pregnancy was associated with a higher prevalence of wheezing and LRTI during the first year of life. Also, the pattern of cleaning product use that discriminated individuals whose mothers tended to use sprays and solvents was associated with a higher prevalence of LRTI and wheezing. The results were not heterogeneous in the four studied cohorts. In the analyses, considering the time window of exposure, the odds of both outcomes were higher for during and after pregnancy exposures to spray and solvents, and for only after pregnancy exposures to air fresheners. However, the ORs remained above 1 when sprays or air fresheners were used during pregnancy, but not during the first year of life. The latter suggests a potential effect of the household use of certain chemical products on foetal development. In this longitudinal study, including cohorts from four regions in Spain, data were collected following a common protocol. We considered a large number of potential confounders in the statistical analyses, thus reducing the possibility of confounding bias. Moreover, we used two related outcomes as independent variables: a diagnosis (LRTI) and a symptom (wheezing). During the first months of life, LRTI is the most common cause of wheezing. The use of both outcomes minimizes the potential of both diagnostic and recall bias. Regarding the exposure, information on the person who used each product and details on the quantity and frequency of use were not obtained. As a result, it is possible that some individuals with very low exposure were classified as exposed.

Furthermore, we need to take into account the possibility of recall bias. Mothers who are particularly concerned about cleanliness may be more exposed to cleaning products and may also recall their child's health status in greater detail than those who are less concerned about cleanliness. On the other hand, in the analyses of postnatal exposures, both the exposures and the outcomes were assessed at the same time. Thus, some individuals reporting respiratory symptoms may overreport the use of some cleaning products. However, the OR obtained for the use of spray and 
Casas, L., Zock, J.P., Carsin, A.E., Fernandez-Somoane, A., Espluques, A., Santa-Marina, L., Tardón, A., Ballester, F., Basterrechea, M., Sunyer, J. The use of household cleaning products during pregnancy and lower respiratory tract infections and wheezing during early life. International Journal of Public Health: 2013, 58(5), 757-764

solvents only after pregnancy were lower or similar to those obtained for the exposure during pregnancy.

We evaluated the potential exposure modification in mothers with asthma, either reducing or increasing the use of these chemicals. We did not find any differences in the use of each product between asthmatic and non-asthmatic mothers. Moreover, stratified analyses showed increased odds for LRTI and wheezing in domestic use of sprays, air fresheners and solvents during pregnancy for both groups (asthmatic and non-asthmatic mothers). In addition, we evaluated the possibility of residual confounding by social class. In fact, the prevalence of wheezing was significantly higher in the lower social class groups, and cleaning products were more frequently used by lower social class participants. However, differences were not consistent for all products. Sprays, air fresheners and solvents showed the smallest differences in use. If residual confounding by social class existed, we would have found associations with other products different from those we obtained. Moreover, stratified analyses for maternal education and social class did not show significant differences in the OR obtained for sprays, air fresheners or solvents use between education and social class groups.

Thus far, most studies on the respiratory effects of cleaning products have focused on professional use (Kogevinas et al. 1999; Medina-Ramón et al. 2003, 2005, 2006; Zock et al. 2010). Fewer studies focused on the household use of these products (Zock et al. 2007, 2009), and very few assessed the effects of using household cleaning products during pregnancy on respiratory symptoms in children. A Belgian cross-sectional study (Nickmilder et al. 2007) found that household use of chlorine bleach was associated with a higher risk of recurrent respiratory infections and a lower risk of atopic sensitisation and asthma amongst 10- to 13-year-old children. In this study, exposure did not necessarily mean exposure to the cleaning product itself, but to the result of its use-a disinfected home environment. Moreover, the results from a recent study in the PARIS (Pollution and Asthma Risk: an Infant Study) cohort suggest that indoor exposure to cleaning sprays may increase the risk of wheezing during the first year of life (Herr et al. 2012).

Three analyses with data from the ALSPAC birth cohort evaluated the use of household cleaning products during pregnancy in relation to health status of the child (Farrow et al. 2003; Henderson et al. 2008; Sherriff et al. 2005); only two of these studies performed analyses in relation to respiratory health (Henderson et al. 2008; Sherriff et al. 2005). The ALSPAC cohort assessed the effects of using household cleaning products during pregnancy on wheezing between birth and 7 years of age. In addition, exposure data were collected by questionnaire during pregnancy. Exposure was calculated using a composite score based on the frequency of use of 11 common household chemicals (Sherriff et al. 2005), rather than assessing the effects of each product separately. This study found an association between maternal exposure and an increase in the incidence of non-transient wheezing from birth to 7 years of age, but it was not possible to determine whether the association was due to pre- or a post-natal exposure because of the high correlation observed between the pre-natal and 8 months' scores.

Our findings are consistent with the results of the ALSPAC study, and there was no indication for heterogeneity between the four INMA cohorts. Furthermore, the INMA study adds the risk assessment of LRTI during infancy in relation to the 
Casas, L., Zock, J.P., Carsin, A.E., Fernandez-Somoane, A., Espluques, A., Santa-Marina, L., Tardón, A., Ballester, F., Basterrechea, M., Sunyer, J. The use of household cleaning products during pregnancy and lower respiratory tract infections and wheezing during early life. International Journal of Public Health: 2013, 58(5), 757-764

exposure to household cleaning products during pregnancy. It remains unclear why some infants with a respiratory infection develop LRTI requiring hospitalization, whilst others only present mild symptoms. Some studies have found an increased risk of LRTI in infants exposed to several outdoor and indoor air pollutants (Karr et al. 2006; Ségala et al. 2008; Smith et al. 2000). Moreover, severe early LRTI have been associated with an increased prevalence of allergic asthma in early adulthood (Sigurs et al. 2010). In this study, we found a clear association between the exposure to cleaning sprays and air fresheners during pregnancy and an increased risk of LRTI in the first year of life, suggesting a potential effect of the use of these products on the development of the immune system during foetal life (Dietert and Zelikoff 2008). Although LRTI and wheezing during early life do not necessarily lead to an onset of asthma during childhood, most children with asthma and reductions in lung function at school age begin with wheezing and have frequent LRTI during the first years of life.

Moreover, exposure to cleaning products in our study population was assessed separately for all products, and using factor analysis-allowing for the combined, rather than only individual, effects of cleaning products to be assessed. In addition, we computed a score of cleaning product use that indicated the number of cleaning products used at home. No statistically significant changes in the risk of LRTI or wheezing during the first year of life were found when including the score in the model. Thus, we reported more detailed information on the specific cleaning products and specific application form related to respiratory outcomes. We found that the household use during pregnancy of certain cleaning products such as solvents, air fresheners and degreasing products, as well as products in spray application form, increased the odds of wheezing and LRTI. However, we did not find any evidence that products such as bleach, ammonia, furniture polishes, glass cleaners and multiuse cleaners had an effect on the infant's respiratory health. In addition, factor analyses including every studied cleaning product grouped all sprayapplied cleaning products and solvents into one factor, suggesting that women who tend to use oven spray also tend to use carpet sprays. When including this factor in the models, we obtained positive and statistically significant associations with both respiratory outcomes.

Application by spraying was the only studied exposure significantly associated with both respiratory outcomes. This application form is likely to facilitate respiratory exposure to both volatile and non-volatile chemical components, and therefore a higher amount of the compound could enter the systemic circulation. Since infants are not active users of cleaning products, this theory could explain the higher odds of infants' respiratory symptoms in relation to the exposure during pregnancy. A higher risk of asthma in adults when exposed to household sprays was also found in the ECRHS (Zock et al. 2007), consistent with our findings.

Infants of mothers who used household chemicals such as solvents, cleaning sprays, air fresheners or degreasing products during pregnancy were more likely to have respiratory symptoms and/or infections during the first year of life. The use of these products in private homes is common and therefore our findings may have significant implications for public health. Further investigation is required to obtain a better exposure assessment and validation of the reported exposure (Zock et al. 2010) and also to identify the underlying pathophysiological mechanisms and the potential 
Casas, L., Zock, J.P., Carsin, A.E., Fernandez-Somoane, A., Espluques, A., Santa-Marina, L., Tardón, A., Ballester, F., Basterrechea, M., Sunyer, J. The use of household cleaning products during pregnancy and lower respiratory tract infections and wheezing during early life. International Journal of Public Health: 2013, 58(5), 757-764

long-term effects of exposure to cleaning chemicals during pregnancy on respiratory health.

\section{Acknowledgments}

This study was funded by grants from the Instituto de Salud Carlos III (Red INMA G03/176, CB06/02/0041, FIS-FEDER 03/1615, 04/1509, 04/1112, 04/1931, 05/1079, 05/1052, 06/1213, 07/0314 and 09/02647), the Conselleria de Sanitat Generalitat Valenciana, the Spanish Ministry of Health (FIS-PI041436, FIS- PI081151, FISSPI042018, FISS-PI09/02311, FIS-PI06/0867 and FIS-PS09/00090), the Generalitat de Catalunya-CIRIT 1999SGR 00241, Obra Social Cajastur, Universidad de Oviedo, Department of Health of the Basque Government (2005111093 and 2009111069), Provincial Government of Gipuzkoa (DFG06/004 and DFG08/001), and Fundación Roger Torné. We acknowledge all the participants in the INMA project for their generous collaboration. A full roster of the INMA Project Investigators can be found at http://www.proyectoinma.org/presentacion-inma/listadoinvestigadores/en_listado-investigadores.html

\section{ELECTRONIC SUPPLEMENTARY MATERIAL}

\section{REFERENCES}

Dietert RR, Zelikoff JT (2008) Early-life environment, developmental immunotoxicology, and the risk of pediatric allergic disease including asthma. Birth Defects Res B Dev Reprod Toxicol 83:547-560. doi:10.1002/bdrb.20170

Farrow A, Taylor H, Northstone K, Golding J (2003) Symptoms of mothers and infants related to total volatile organic compounds in household products. Arch Environ Health 58:633-641. doi:10.3200/AEOH.58.10.633-641

Henderson J, Sherriff A, Farrow A, Ayres JG (2008) Household chemicals, persistent wheezing and lung function: effect modification by atopy? Eur Respir J 31:547-554. doi:10.1183/09031936.00086807

Herr M, Just J, Nikasinovic L et al (2012) Influence of host and environmental factors on wheezing severity in infants: findings from the PARIS birth cohort. Clin Exp Allergy 42:275283. doi:10. 1111/j.1365-2222.2011.03933.x

Jaakkola JJK, Jaakkola MS (2006) Professional cleaning and asthma. Curr Opin Allergy Clin Immunol 6:85-90. doi:10.1097/01.all.0000216849.64828.55

Karr C, Lumley T, Shepherd K et al (2006) A case-crossover study of wintertime ambient air pollution and infant bronchiolitis. Environ Health Perspect 114:277-281PubMedCrossRef

Kogevinas M, Antó JM, Sunyer J et al (1999) Occupational asthma in Europe and other industrialised areas: a population-based study. European Community Respiratory Health Survey Study Group. Lancet 353:1750-1754

Medina-Ramón M, Zock JP, Kogevinas M et al (2003) Asthma symptoms in women employed in domestic cleaning: a community based study. Thorax 58:950-954

Medina-Ramón M, Zock JP, Kogevinas M et al (2005) Asthma, chronic bronchitis, and exposure to irritant agents in occupational domestic cleaning: a nested case-control study. Occup Environ Med 62:598-606. doi:10.1136/oem.2004.017640

Medina-Ramón M, Zock JP, Kogevinas M et al (2006) Short-term respiratory effects of cleaning exposures in female domestic cleaners. Eur Respir J 27:1196-1203. doi:10.1183/09031936.06.00085405

Nickmilder M, Carbonnelle S, Bernard A (2007) House cleaning with chlorine bleach and the risks of allergic and respiratory diseases in children. Pediatr Allergy Immunol 18:27-35. doi:10.1111/j.1399-3038.2006.00487.x 
Casas, L., Zock, J.P., Carsin, A.E., Fernandez-Somoane, A., Espluques, A., Santa-Marina, L., Tardón, A., Ballester, F., Basterrechea, M., Sunyer, J. The use of household cleaning products during pregnancy and lower respiratory tract infections and wheezing during early life. International Journal of Public Health: 2013, 58(5), 757-764

Ribas-Fitó N, Ramón R, Ballester F et al (2006) Child health and the environment: the INMA Spanish Study. Paediatr Perinat Epidemiol 20:403-410. doi:10.1111/i.13653016.2006.00745.X

Ségala C, Poizeau D, Mesbah M et al (2008) Winter air pollution and infant bronchiolitis in Paris. Environ Res 106:96-100. doi:10.1016/..envres.2007.05.003

Sherriff A, Farrow A, Golding J, Henderson J (2005) Frequent use of chemical household products is associated with persistent wheezing in pre-school age children. Thorax 60:4549. doi:10.1136/thx.2004.021154

Sigurs N, Aljassim F, Kjellman B et al (2010) Asthma and allergy patterns over 18 years after severe RSV bronchiolitis in the first year of life. Thorax 65:1045-1052. doi:10.1136/thx.2009.121582

Smith KR, Samet JM, Romieu I, Bruce N (2000) Indoor air pollution in developing countries and acute lower respiratory infections in children. Thorax 55:518-532

Sunyer J, Garcia-Esteban R, Alvarez M et al (2010) DDE in mothers' blood during pregnancy and lower respiratory tract infections in their infants. Epidemiology 21:729-735. doi:10.1097/EDE.0b013e3181e5ea96

Zock J-P, Plana E, Jarvis D et al (2007) The use of household cleaning sprays and adult asthma: an international longitudinal study. Am J Respir Crit Care Med 176:735-741. doi:10.1164/rccm.200612-17930C

Zock J-P, Plana E, Antó JM et al (2009) Domestic use of hypochlorite bleach, atopic sensitization, and respiratory symptoms in adults. J Allergy Clin Immunol 124(731-738):e1. doi:10.1016/j.jaci.2009.06.007

Zock J-P, Vizcaya D, Le Moual N (2010) Update on asthma and cleaners. Curr Opin Allergy Clin Immunol 10:114-120. doi:10.1097/ACl.0b013e32833733fe 
Casas, L., Zock, J.P., Carsin, A.E., Fernandez-Somoane, A., Espluques, A., Santa-Marina, L., Tardón, A., Ballester, F., Basterrechea, M., Sunyer, J. The use of household cleaning products during pregnancy and lower respiratory tract infections and wheezing during early life. International Journal of Public Health: 2013, 58(5), 757-764

TABLES

Table 1: Description (\%) of the study population (Asturias, Gipuzkoa, Sabadell and Valencia, 20032009)

\begin{tabular}{|c|c|c|c|c|c|}
\hline & $\begin{array}{l}\text { Asturias } \\
\mathrm{n}=\mathbf{4 5 0}\end{array}$ & $\begin{array}{l}\text { Gipuzkoa } \\
\mathrm{n}=556\end{array}$ & $\begin{array}{l}\text { Sabadell } \\
n=579\end{array}$ & $\begin{array}{l}\text { Valencia } \\
\mathbf{n}=707\end{array}$ & $\begin{array}{l}\text { Total } \\
\mathbf{n}=2,292\end{array}$ \\
\hline Sex (boys) & 52.0 & 50.4 & 51.3 & 52.8 & 51.7 \\
\hline \multicolumn{6}{|l|}{ Maternal education } \\
\hline Primary education or below & 17.8 & 12.4 & 27.3 & 31.7 & 23.2 \\
\hline Secondary education & 44.0 & 36.0 & 42.5 & 43.4 & 41.5 \\
\hline University education or more & 38.2 & 51.6 & 30.2 & 24.9 & 35.3 \\
\hline LRTI during the first year of life & 32.2 & 33.5 & 34.2 & 28.0 & 31.7 \\
\hline Wheezing during the first year of life & 50.0 & 34.4 & 34.7 & 25.6 & 34.8 \\
\hline \multicolumn{6}{|l|}{ Cleaning products use during pregnancy } \\
\hline Bleach & 76.4 & 58.6 & 72.5 & 91.8 & 75.9 \\
\hline Ammonia & 43.3 & 13.3 & 23.9 & 56.1 & 35.1 \\
\hline Solvents & 20.0 & 20.0 & 29.2 & 39.8 & 28.4 \\
\hline Furniture polishes & 50.7 & 45.5 & 41.9 & 65.8 & 51.9 \\
\hline Glass cleaners & 72.9 & 60.1 & 76.7 & 91.1 & 76.4 \\
\hline Air fresheners & 46.7 & 55.4 & 71.3 & 85.9 & 67.1 \\
\hline Multiuse cleaners & 57.8 & 84.7 & 60.5 & 66.4 & 67.7 \\
\hline Degreasing products & - & 69.6 & 71.2 & - & $70.4^{\mathrm{b}}$ \\
\hline Sprays $^{\mathrm{a}}$ & 33.8 & 39.6 & 31.8 & 66.5 & 44.8 \\
\hline Ironing spray & 6.2 & 4.7 & 8.5 & 15.7 & 9.3 \\
\hline Oven spray & 22.4 & 17.8 & 12.7 & 36.2 & 23.1 \\
\hline Carpet spray & 8.4 & 3.4 & 3.0 & 10.8 & 6.6 \\
\hline Floor spray & 11.1 & 22.1 & 14.9 & 38.3 & 23.1 \\
\hline
\end{tabular}

LRTI lower respiratory tract infections

${ }^{\mathrm{a}}$ Use of ironing, oven, carpet or floor cleaning sprays

${ }^{\mathrm{b}}$ Total number $=1,141$ 
Casas, L., Zock, J.P., Carsin, A.E., Fernandez-Somoane, A., Espluques, A., Santa-Marina, L., Tardón, A., Ballester, F., Basterrechea, M., Sunyer, J. The use of household cleaning products during pregnancy and lower respiratory tract infections and wheezing during early life. International Journal of Public Health: 2013, 58(5), 757-764

Table 2: Association between cleaning product use and patterns of use during pregnancy and LRTI and wheezing during the first year of life. Adjusted odds ratios (OR) and $95 \%$ confidence intervals (95 \% $\mathrm{CI})$ and heterogeneity $\mathrm{p}$ values for each of the studied cleaning products and groups of cleaning products' use, resulting from the meta-analyses including the four cohorts in the study (Asturias, Gipuzkoa, Sabadell and Valencia, 2003-2009)

\begin{tabular}{|l|l|l|l|l|l|}
\hline \multicolumn{1}{|c|}{} & LRTI & Wheezing & \\
\cline { 2 - 4 } & OR (95 \% CI) & p heterogeneity & OR (95 \% CI) & p heterogeneity \\
\hline Cleaning products use & & & & \\
\hline Bleach & $0.91(0.71-1.17)$ & 0.52 & $0.91(0.72-1.17)$ & 0.81 \\
\hline Ammonia & $1.03(0.82-1.29)$ & 0.32 & $1.00(0.80-1.26)$ & 0.07 \\
\hline Solvents & $1.19(0.95-1.48)$ & 0.06 & $1.30(1.03-1.62)$ & 0.78 \\
\hline Furniture polishes & $0.99(0.81-1.22)$ & 0.52 & $1.01(0.82-1.24)$ & 0.52 \\
\hline Glass cleaners & $0.92(0.72-1.18)$ & 0.62 & $0.94(0.74-1.20)$ & 0.23 \\
\hline Air fresheners & $1.29(1.03-1.63)$ & 0.41 & $1.09(0.87-1.37)$ & 0.41 \\
\hline Multiuse cleaners & $0.92(0.74-1.15)$ & 0.11 & $0.91(0.73-1.13)$ & 0.63 \\
\hline Degreasing products ${ }^{\mathrm{a}}$ & $1.23(0.90-1.69)$ & 0.88 & $1.32(0.97-1.79)$ & 0.83 \\
\hline Sprays & $1.29(1.04-1.59)$ & 0.29 & $1.37(1.10-1.69)$ & 0.60 \\
\hline Pattern of use & & & \\
\hline $\begin{array}{l}\text { Factor } 1 \text { (furniture polishes, glass } \\
\text { cleaners and air fresheners) }\end{array}$ & $0.97(0.75-1.24)$ & 0.28 & $0.93(0.73-1.92)$ & 0.09 \\
\hline Factor 2 (spray and solvents) & $1.54(1.11-2.14)$ & 0.11 & $1.68(1.21-2.35)$ & 0.85 \\
\hline Factor 3 (bleach and ammonia) & $0.99(0.62-1.57)$ & 0.02 & $1.01(0.78-1.30)$ & 0.33 \\
\hline
\end{tabular}

Adjusted for sex, month of birth, parity, breast feeding, day care attendance, maternal smoking history, maternal age, country of origin of the mother, maternal education, maternal asthma and maternal atopy

LRTI lower respiratory tract infections

${ }^{\mathrm{a}}$ Only including Gipuzkoa and Sabadell cohorts 
Casas, L., Zock, J.P., Carsin, A.E., Fernandez-Somoane, A., Espluques, A., Santa-Marina, L., Tardón, A., Ballester, F., Basterrechea, M., Sunyer, J. The use of household cleaning products during pregnancy and lower respiratory tract infections and wheezing during early life. International Journal of Public Health: 2013, 58(5), 757-764

Fig. 1: Association between the household use of sprays, solvents and air fresheners during pregnancy and the prevalence of wheezing and lower respiratory tract infections (LRTI) by cohort. Odds ratio (OR) and $95 \%$ confidence interval (CI) adjusted for sex, month of birth, parity, breast feeding, day care attendance, maternal smoking history, maternal age, country of origin of the mother, maternal education, maternal asthma and maternal atopy. Diamond indicates $95 \% \mathrm{CI}$ of the combined OR from the model (Asturias, Gipuzkoa, Sabadell and Valencia 2003-2009)

LRTI

Asturias

Gipuzkoa

Sabadell

Valencia

Combined

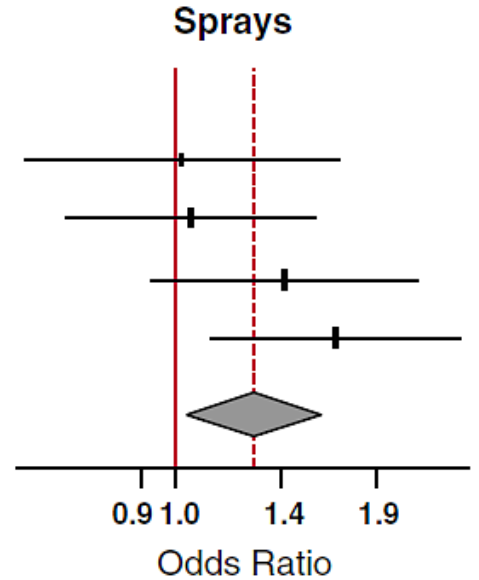

Wheezing

Asturias

Gipuzkoa

Sabadell

Valencia

Combined

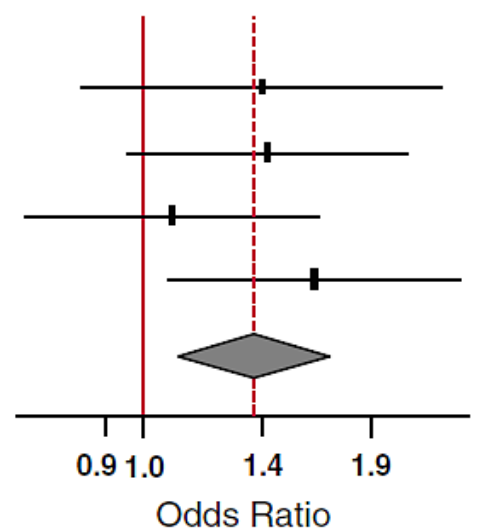

Solvents
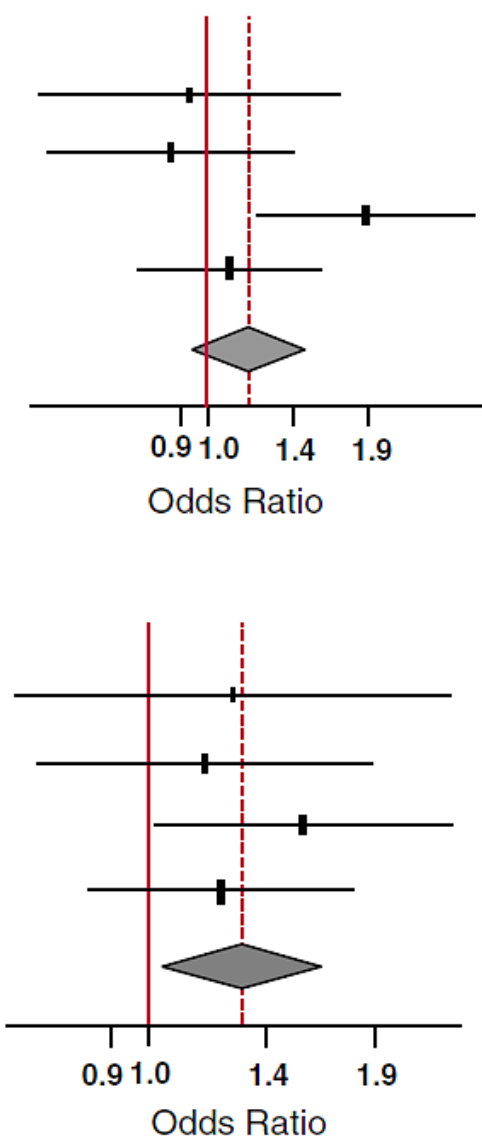
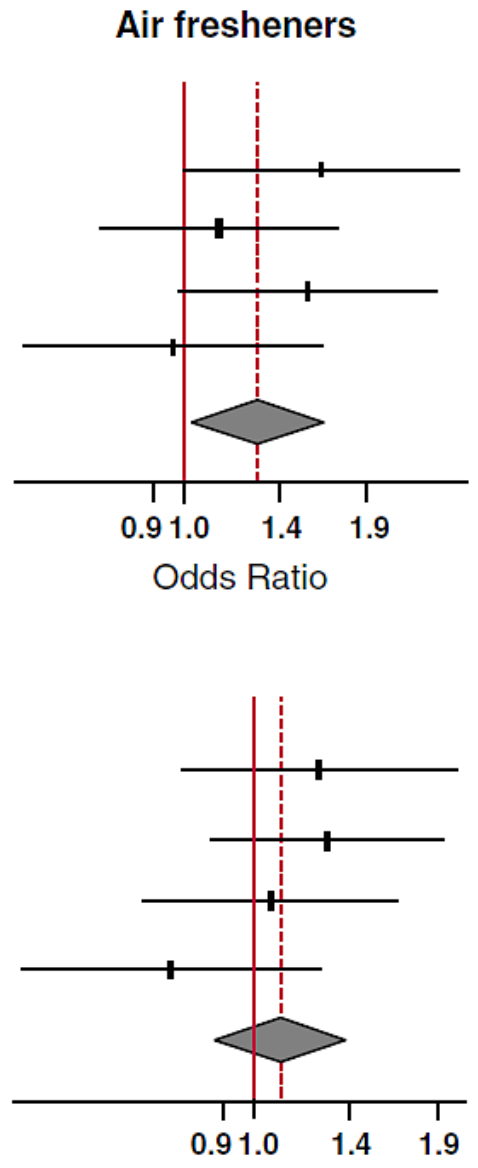

Odds Ratio 
Casas, L., Zock, J.P., Carsin, A.E., Fernandez-Somoane, A., Espluques, A., Santa-Marina, L., Tardón, A., Ballester, F., Basterrechea, M., Sunyer, J. The use of household cleaning products during pregnancy and lower respiratory tract infections and wheezing during early life. International Journal of Public Health: 2013, 58(5), 757-764

Table 3: Description, adjusted odds ratios (OR) and $95 \%$ confidence intervals (95\%CI) for household use of sprays, solvents and air fresheners according to the time window of use (during pregnancy and after pregnancy), resulting from the pooled analyses including two cohorts in the study (Asturias and Valencia, 2003-2009) $(\mathrm{n}=1,157)$

\begin{tabular}{|l|l|l|l|}
\hline \multicolumn{1}{|c|}{} & LRTI & Wheezing \\
\hline Spray & OR (95 \% CI) & OR (95 \% CI) \\
\hline Only during pregnancy & $341(29.5)$ & $1.19(0.82-1.73)$ & $1.62(1.11-2.36)$ \\
\hline Only after pregnancy & $103(8.9)$ & $0.90(0.53-1.55)$ & $1.34(0.80-2.24)$ \\
\hline During pregnancy and after & $281(24.3)$ & $1.43(0.97-2.13)$ & $1.61(1.08-2.41)$ \\
\hline Solvents & & & \\
\hline Only during pregnancy & $232(23.3)$ & $0.94(0.65-1.38)$ & $1.04(0.71-1.51)$ \\
\hline Only after pregnancy & $132(13.2)$ & $1.06(0.67-1.66)$ & $0.87(0.55-1.37)$ \\
\hline During pregnancy and after & $58(5.8)$ & $1.35(0.73-2.50)$ & $1.81(0.98-3.37)$ \\
\hline Air fresheners & & & $1.39(0.85-2.29)$ \\
\hline Only during pregnancy & $197(18.5)$ & $1.31(0.77-2.21)$ & $1.75(1.01-3.04)$ \\
\hline Only after pregnancy & $114(10.7)$ & $1.85(1.04-3.30)$ & $1.23(0.79-1.93)$ \\
\hline During pregnancy and after & $568(53.4)$ & $1.59(1.00-2.55)$ & \\
\hline Adjusted for & & & \\
\hline
\end{tabular}

Adjusted for cohort, sex, month of birth, parity, breast feeding, day care attendance, maternal smoking history, maternal age, country of origin of the mother, maternal education, maternal asthma and maternal atopy

LRTI lower respiratory tract infections 


\section{ONLINE SUPPLEMENT TABLES:}

Table 1. Description of the prevalence ( $n(\%)$ ) of LRTI (lower respiratory tract infections) $(n=2162)$ and wheezing ( $n=2147)$ at the age of 14 months, according to the use of the studied cleaning products during pregnancy in each birth cohort. (Asturias, Gipuzkoa, Sabadell and Valencia, 2003 - 2009)

\begin{tabular}{|c|c|c|c|c|c|c|c|c|}
\hline & \multicolumn{2}{|c|}{ Asturias } & \multicolumn{2}{|c|}{ Gipuzkoa } & \multicolumn{2}{|c|}{ Sabadell } & \multicolumn{2}{|c|}{ Valencia } \\
\hline & not users & users & not users & users & not users & users & not users & users \\
\hline \multicolumn{9}{|l|}{ LRTI* } \\
\hline Bleach & $36(36.0)$ & $109(35.4)$ & $75(36.2)$ & $111(36.8)$ & $58(38.7)$ & $140(34.9)$ & $13(23.2)$ & $185(29.0)$ \\
\hline Ammonia & $86(36.6)$ & $59(34.1)$ & $162(36.8)$ & $24(34.8)$ & $148(35.2)$ & $50(38.2)$ & $76(24.8)$ & $122(31.7)$ \\
\hline Solvents & $113(35.0)$ & $32(37.7)$ & $149(36.8)$ & $37(35.6)$ & $124(31.9)$ & $74(45.7)$ & $115(27.6)$ & $83(30.1)$ \\
\hline Furniture polishes & 65 (32.2) & $80(38.8)$ & $105(37.6)$ & $81(35.2)$ & $119(36.6)$ & $79(35.0)$ & $67(28.0)$ & $131(28.9)$ \\
\hline Glass cleaners & $38(34.2)$ & $107(36.0)$ & $71(34.5)$ & $115(38.0)$ & $58(44.6)$ & $140(33.2)$ & $20(32.8)$ & $178(28.2)$ \\
\hline Air fresheners & $71(32.3)$ & $74(39.4)$ & $86(38.9)$ & $100(34.7)$ & $52(32.7)$ & $146(37.2)$ & $27(27.3)$ & $171(28.8)$ \\
\hline Multi-use cleaners & $61(35.7)$ & $84(35.4)$ & $25(32.5)$ & $161(37.3)$ & $79(36.4)$ & $119(35.7)$ & $80(34.5)$ & $117(25.4)$ \\
\hline Degreasing products & - & - & $53(33.5)$ & $133(37.9)$ & $54(33.1)$ & $144(37.0)$ & - & - \\
\hline Sprays** & $97(35.9)$ & $48(34.8)$ & $108(34.8)$ & $78(39.2)$ & $131(34.5)$ & $67(39.0)$ & $54(23.5)$ & $144(31.1)$ \\
\hline \multicolumn{9}{|l|}{ Wheezing } \\
\hline Bleach & $52(59.1)$ & $173(57.5)$ & $83(38.4)$ & $108(34.4)$ & $55(38.5)$ & $146(38.4)$ & $15(25.9)$ & $166(25.7)$ \\
\hline Ammonia & $125(56.1)$ & $100(60.2)$ & $168(36.6)$ & $23(32.4)$ & $144(36.0)$ & $57(46.3)$ & $88(28.5)$ & $93(23.6)$ \\
\hline Solvents & 179 (57.2) & $46(60.5)$ & $150(35.3)$ & $41(39.1)$ & 133 (35.6) & $68(45.6)$ & $103(24.4)$ & $78(27.8)$ \\
\hline Furniture polishes & 108 (56.5) & 117 (59.1) & $102(35.3)$ & 89 (36.9) & 119 (38.3) & $82(38.7)$ & $64(26.6)$ & $117(25.3)$ \\
\hline Glass cleaners & 60 (57.1) & 165 (58.1) & $70(33.0)$ & $121(38.1)$ & $56(44.4)$ & $145(36.4)$ & $21(33.9)$ & $160(24.9)$ \\
\hline Air fresheners & $116(56.9)$ & 109 (58.9) & $84(36.4)$ & $107(35.8)$ & $57(39.0)$ & $144(38.2)$ & $28(28.0)$ & $153(25.3)$ \\
\hline Multi-use cleaners & 102 (61.8) & $123(54.9)$ & $26(32.5)$ & $165(36.7)$ & $84(39.8)$ & $117(37.6)$ & $66(28.2)$ & $115(24.5)$ \\
\hline Degreasing products & - & - & $52(32.3)$ & $139(37.7)$ & $49(32.5)$ & $152(40.8)$ & - & - \\
\hline Sprays** & $144(56.0)$ & $81(61.4)$ & $105(32.8)$ & $86(41.0)$ & $134(37.8)$ & $67(39.6)$ & 49 (20.9) & $132(28.1)$ \\
\hline
\end{tabular}

*LRTI: lower respiratory tract infections

**Use of ironing, oven, carpet or floor cleaning sprays. 
Table 2. Crude associations (OR) and p-values between the potential confounders and lower respiratory tract infections (LRTI) during the first year of life. (Asturias, Gipuzkoa, Sabadell and Valencia, 2003 - 2009)

\begin{tabular}{|c|c|c|c|c|c|c|c|c|}
\hline & \\
\hline & \multicolumn{2}{|c|}{ ASTURIAS } & \multicolumn{2}{|c|}{ GIPUZKOA } & \multicolumn{2}{|c|}{ SABADELL } & \multicolumn{2}{|c|}{ VALENCIA } \\
\hline & OR & $p$-value & OR & p-value & OR & p-value & OR & p-value \\
\hline Male & 2.13 & 0.00 & 1.20 & 0.32 & 1.59 & 0.01 & 2.00 & 0.00 \\
\hline Birth weight (kg) & 2.40 & 0.00 & 1.26 & 0.27 & 1.13 & 0.59 & 1.15 & 0.40 \\
\hline Born between November and May & 0.68 & 0.08 & 0.67 & 0.03 & 0.88 & 0.47 & 0.78 & 0.14 \\
\hline One or more previous pregnancies (ref: first pregnancy) & 0.55 & 0.05 & 0.42 & 0.06 & 0.99 & 0.00 & 0.86 & 0.00 \\
\hline \multicolumn{9}{|l|}{ Predominant breast feeding (ref: no breast feeding) } \\
\hline Breast feeding $<16$ weeks & 0.85 & 0.52 & 1.12 & 0.71 & 0.56 & 0.03 & 1.09 & 0.71 \\
\hline Breast feeding 16 to 24 weeks & 0.49 & 0.04 & 1.20 & 0.55 & 0.58 & 0.03 & 0.72 & 0.17 \\
\hline Breast feeding $>24$ weeks & - & - & 1.01 & 0.99 & 1.16 & 0.67 & 0.75 & 0.33 \\
\hline Day care at the age of 1 years & 0.99 & 0.96 & 1.33 & 0.12 & 2.51 & 0.00 & 1.69 & 0.01 \\
\hline \multicolumn{9}{|l|}{ Maternal smoking (ref: never smoker) } \\
\hline Smoker only after delivery & 0.93 & 0.83 & 1.06 & 0.86 & 1.49 & 0.13 & 0.86 & 0.59 \\
\hline Smoker only during pregnancy & 1.67 & 0.72 & - & - & - & - & 3.31 & 0.04 \\
\hline Smoker during both periods & 1.10 & 0.74 & 0.83 & 0.54 & 1.37 & 0.25 & 1.67 & 0.01 \\
\hline Gas heating & 1.2 & 0.48 & 0.71 & 0.13 & 1.2 & 0.42 & 1.4 & 0.05 \\
\hline Country of origin of the mother: not European (ref: European) & 0.23 & 0.17 & 0.74 & 0.66 & 0.75 & 0.41 & 0.84 & 0.58 \\
\hline \multicolumn{9}{|l|}{ Maternal eduction (ref: primary or less) } \\
\hline Secondary & 1.14 & 0.66 & 1.81 & 0.06 & 1.10 & 0.68 & 0.64 & 0.02 \\
\hline University & 0.77 & 0.40 & 1.65 & 0.10 & 1.00 & 0.99 & 0.55 & 0.01 \\
\hline Maternal asthma & 1.85 & 0.12 & 2.24 & 0.04 & 0.83 & 0.58 & 2.98 & 0.00 \\
\hline Maternal atopy & 0.74 & 0.22 & 1.22 & 0.32 & 1.15 & 0.45 & 1.10 & 0.59 \\
\hline Maternal age at birth & 0.98 & 0.44 & 0.97 & 0.33 & 1.05 & 0.03 & 1.02 & 0.21 \\
\hline
\end{tabular}

*LRTI: lower respiratory tract infections 
Table 3. Crude associations (OR) and p-values between the potential confounders and wheezing during the first year of life. (Asturias, Gipuzkoa, Sabadell and Valencia, 2003 - 2009).

Wheezing

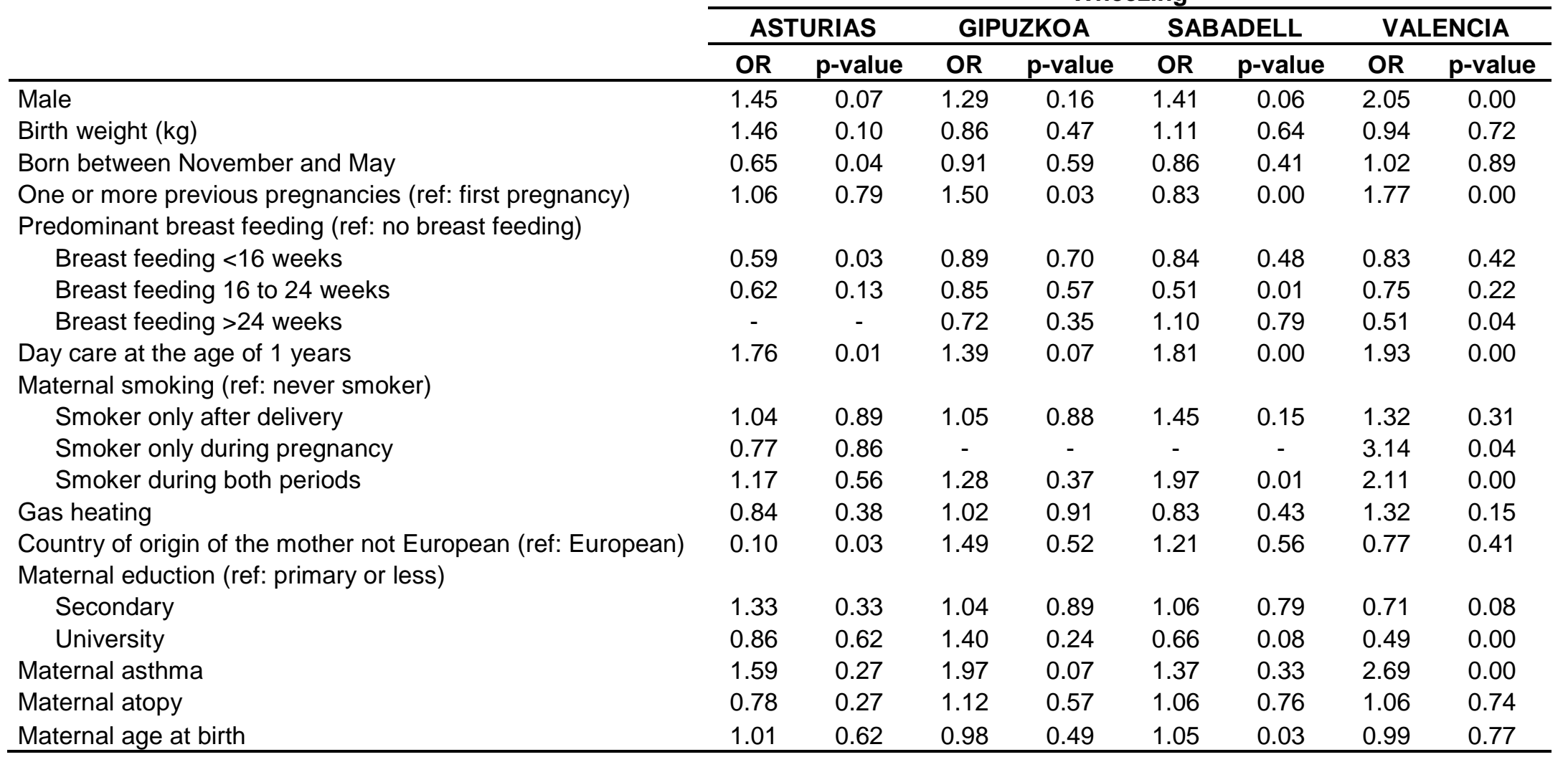


Table 4. Factor analyses: rotated factor loadings (pattern matrix) and unique variances. (Asturias, Gipuzkoa, Sabadell and Valencia, 2003 - 2009).

Factor 1 Factor 2 Factor 3 uniqueness

\begin{tabular}{lcccc}
\hline Bleach & 0.43 & 0.20 & 0.64 & 0.37 \\
Ammonia & 0.18 & 0.08 & 0.79 & 0.34 \\
Solvents & 0.19 & 0.55 & -0.02 & 0.66 \\
Furniture polishes & 0.65 & 0.31 & 0.02 & 0.48 \\
Glass cleaners & 0.85 & 0.09 & 0.15 & 0.25 \\
Carpet spray & 0.17 & 0.72 & 0.04 & 0.46 \\
Floor cleaning spray & 0.31 & 0.40 & 0.23 & 0.70 \\
Oven spray & 0.37 & 0.49 & 0.11 & 0.61 \\
Air fresheners & 0.65 & 0.17 & 0.05 & 0.55 \\
Ironing spray & -0.01 & 0.75 & 0.02 & 0.44 \\
Multi-use cleaners & 0.44 & 0.13 & -0.64 & 0.38 \\
\hline
\end{tabular}

